\title{
Efficiency Control in Iridium Complex-Based Phosphorescent Light-Emitting Diodes
}

\author{
Boucar Diouf, ${ }^{1}$ Woo Sik Jeon, ${ }^{1}$ Ramchandra Pode, ${ }^{2}$ and Jang Hyuk Kwon ${ }^{1}$ \\ ${ }^{1}$ Department of Information Display, Kyung Hee University, Dongdaemoon-gu, Seoul 130-701, Republic of Korea \\ ${ }^{2}$ Department of Physics, Kyung Hee University, Dongdaemoon-gu, Seoul 130-701, Republic of Korea \\ Correspondence should be addressed to Jang Hyuk Kwon, jhkwon@khu.ac.kr
}

Received 23 February 2012; Accepted 2 May 2012

Academic Editor: Etienne Baranoff

Copyright ( 2012 Boucar Diouf et al. This is an open access article distributed under the Creative Commons Attribution License, which permits unrestricted use, distribution, and reproduction in any medium, provided the original work is properly cited.

\begin{abstract}
Key factors to control the efficiency in iridium doped red and green phosphorescent light emitting diodes (PhOLEDs) are discussed in this review: exciton confinement, charge trapping, dopant concentration and dopant molecular structure. They are not independent from each other but we attempt to present each of them in a situation where its specific effects are predominant. A good efficiency in PhOLEDs requires the triplet energy of host molecules to be sufficiently high to confine the triplet excitons within the emitting layer (EML). Furthermore, triplet excitons must be retained within the EML and should not drift into the nonradiative levels of the electron or hole transport layer (resp., ETL or HTL); this is achieved by carefully choosing the EML's adjacent layers. We prove how reducing charge trapping results in higher efficiency in PhOLEDs. We show that there is an ideal concentration for a maximum efficiency of PhOLEDs. Finally, we present the effects of molecular structure on the efficiency of PhOLEDs using red iridium complex dopant with different modifications on the ligand to tune its highest occupied molecular orbital (HOMO) and lowest unoccupied molecular orbital (LUMO) energies.
\end{abstract}

\section{Introduction}

Achievements in organic light emitting diodes (OLEDs) lead to their integration as displays in several electronic devices and make them serious candidates to replace widely used LCD panels. Extensive research efforts have been made for higher achievements in organic displays both in industrial and academic fields [1-10].

In organic light-emitting devices (OLEDs), injected electrons and holes in the emitter will attract each other to form excitons [11-20]. Spin statistics demonstrate that the ratio between singlet and triplet excitons is one to three. In fluorescent OLEDs only the singlet excitons can generate radiative recombinations, giving a maximum inherent quantum efficiency of $25 \%$ [21-23], with no phosphorescent light radiation. On the other hand, triplet emitters can harvest both singlet and triplet radiative recombinations reaching a theoretical internal quantum efficiency of $100 \%$ [24-26]. Iridium and platinum complexes present good phosphorescent emission properties [27-29]. Iridium (III) complexes are the most widely used dopants in PhOLEDs because of their higher triplet efficiency [30-35].
PhOLEDs harvest both singlet and triplet emissions, making it possible to reach high efficiency devices. However, their operation and efficient implementation are more complex than for the fluorescent OLEDs.

To achieve high efficiency in PhOLEDs, the host material that forms the EML needs to satisfy a certain number of properties regarding the dopant as well as the adjacent layers. In PhOLEDs, the HOMOs and LUMOs of the host and phosphorescent emitter dopant have to be carefully selected to achieve a good exciton confinement within the EML. As well, a particular attention should be given to the origins and effects of charge trapping, concentration of the dopant, exciton quenching and the molecular structure of the dopant for a better control of the PhOLEDs' efficiency.

In fact, beside a fast decay of triplet dopant, the host materials need to have an energy gap wide enough to allow efficient energy transfers with the dopant (Figure 1) but should not induce charge trapping. A tradeoff is necessary between the width of the gap of the host material and the energy levels of the adjacent layers in order to allow good electrons and holes injection. The host material should as 


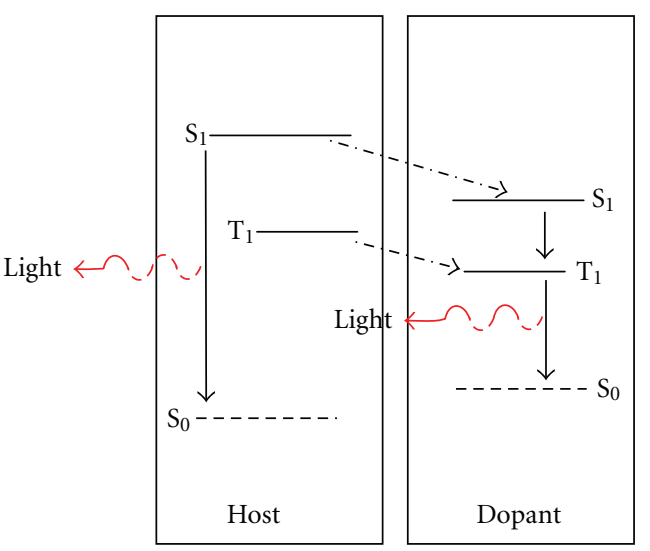

Figure 1: Energy structure between host and dopant in a PhOLED, $S_{1}$ represents the singlet excited states, $T_{1}$ the triplet excited states, and $\mathrm{S}_{0}$ the ground states.

well present equivalent transport properties for electrons and holes for a balanced number of opposite carriers to recombine efficiently.

The excitation energy will efficiently transfer from the host to the triplet energy of the dopant when the triplet energy of the dopant is lower than the triplet energy of the host. The triplet excitons confinement in the dopant will make it possible to observe the phosphorescent light emission [36]. To maximize the performance of PhOLEDs, the dopant should be uniformly dispersed in the host matrix to minimize the exciton quenching or triplet-triplet annihilation [37].

The guest molecules are believed to act potentially as charge traps for electrons and holes in the EML, resulting in an increase of the driving voltage [31]. Two processes of electroluminescence in the doped EML exist. Light emission can be from the energy transfer from the host to the dopant or from trapped charges in the dopant. In the latter situation, it is assumed that the dopant molecules will act as recombination centers attracting charges by coulomb interaction if the radius of separation is within a certain range. Charge trapping effects can be observed with the presence of a large barrier at the interface between a carrier transport layer and the host material or when the gap between the host and the dopant HOMO and LUMO energy levels is too wide.

A high doping concentration minimizes the charge trapping but results in exciton quenching thereby lowering the efficiency of the light emitting device [31]. Therefore, a good balance between charge trapping, charge mobility for the recombination zone in the emissive layer, and a low enough doping concentration to avoid efficiency loss due to exciton quenching is desirable.

Triplet confinement may be controlled in two ways, namely, within the EML itself and then by the adjacent layers. The confinement in the EML is achieved when the guess material has its HOMO and LUMO levels within the band gap of the host material $[31,38]$. While the adjacent layers will play the role of electron blocking layer so that, the electrons from the cathode will not drift beyond the EML and holes from the anode will not go beyond the EML. Such a confinement arrangement will give a higher probability of recombination between the electrons and holes within the EML [38].

The objective of this paper based on our research activities is to present our investigations to control the efficiency in PhOLEDs through triplet exciton confinement, minimization of charge trapping, doping concentration, and dopant molecules design to limit self-quenching. Results are presented in their decreasing order of influence on the efficiency of the PhOLEDs. Excitons confinement needs to be adjusted before the reduction of charge trapping. Charge trapping needs to be minimized before setting the optimum doping concentration. Finally, the dopant molecular structure will act as a fine tuner in the improvement of the efficiency of the PhOLEDs.

\section{Devices Fabrication and Characterization}

The samples presented in this paper were fabricated on a clean glass substrate precoated with $150 \mathrm{~nm}$ thick film of indium tin oxide (ITO) with a sheet resistance of $12 \Omega /$ square. The ITO film and organic insulator for covering ITO edge area were patterned by standard photolithography techniques and then clean by sonification in isopropyl alcohol and acetone, rinsed in deionized water before being irradiated in a UV-ozone chamber.

All organic materials were deposited by thermal vacuum evaporation technique under a pressure of about $10^{-7}$ Torr at a rate of $1 \AA / \mathrm{s}$. Finally, $\mathrm{LiF}$ and $\mathrm{Al}$ were deposited to form the counterelectrode in another adjacent vacuum deposition chamber without breaking the vacuum; at a rate of $0.1 \AA / \mathrm{s}$ for $\mathrm{LiF}$ and $5-10 \AA / \mathrm{s}$ for $\mathrm{Al}$.

The OLEDs active surface area is $2 \times 2 \mathrm{~mm}^{2}$. Current density-voltage $(J-V)$ characteristics were measured using a Keithley SMU 2635A; the luminescence-voltage $(L-V)$ curves using a Minolta CA-100A, the Electroluminescence (EL), and CIE coordinate were obtained using a Minolta CS-1000A Spectroradiometer.

\section{Excitons Confinement}

To achieve excitons confinement in PhOLEDs, it is necessary to have a good control of the triplet excitons diffusion at the interfaces between the carrier transport layers and the EML. Such an achievement translates in practical in the fact that the electrons from the cathode and the holes from the anode do not travel beyond the emissive layer where the radiative recombination should take place $[39,40]$. In such conditions, the adjacent layer that injects electrons in the EML should form a barrier of potential for the holes. Similarly, the hole injection layer should be a barrier of potential for the electrons as depicted Figure 2. The charge transport layer can ideally be the charge injection layer for a simpler device.

This type of arrangement imposes constraints in the combination of adjacent layers (with good charge transport properties) and the EML in regard of the relative position of their HOMO and LUMO levels. The use of wide band-gap host materials may be necessary in PhOLEDs [41-45] for the 


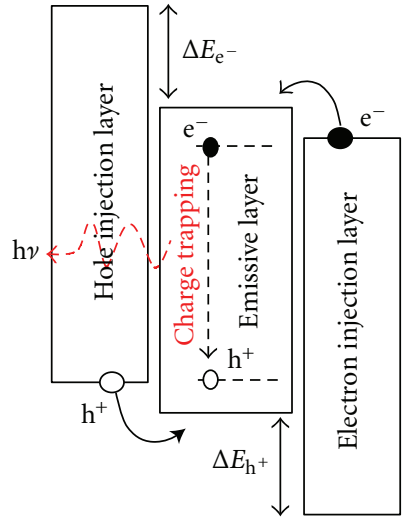

Figure 2: Excitons confinement in the emissive layer by the adjacent layer, $\Delta E_{\mathrm{e}^{-}}$is the energy barrier for electrons, and $\Delta E_{\mathrm{h}^{+}}$the energy barrier for the holes with charge trapping.

good energy transfer from the host to the dopant. This necessity induces a certain number of difficulties. When a wide band-gap material is used as a host material for the emitting layer, the carrier mobility decreases significantly since dopant molecules act as charge trapping sites [46]. To overcome such an issue, a high doping concentration of over $7 \%$ in green PHOLEDs may be required to make a good balanced current flow through dopant molecules. In such devices, exciton self-quenching and triplet-triplet annihilation by high doping concentration are unavoidable problems. For instance, when the doping concentration is increased from 2 to $6 \%$, the phosphorescence photoluminescence quantum efficiency of tris(2-phenylpyridine)iridium $\left(\operatorname{Ir}(\mathrm{ppy})_{3}\right)$ is decreased by $5 \%$ [47]. Good excitons confinement is very difficult when making PhOLEDs with wide band-gap host materials. To overcome these constraints, a narrow band-gap host of 4, $4^{\prime}-\mathrm{N}, \mathrm{N}^{\prime}$-dicarbazoleterpheyl (CTP) was developed by our group [48]. In this study, we report highly efficient green phosphorescent devices comprising a triplet exciton confinement configuration using our CTP host with high triplet energy charge transporting layers. The maximum current and power efficiencies of $56.89 \mathrm{~cd} / \mathrm{A}$, and $48.22 \mathrm{~lm} / \mathrm{W}$ with $18 \%$ external quantum efficiency (EQE) are realized by this good triplet exciton confinement configuration by minimization of self-quenching.

In order to make a better triplet exciton confinement configuration in green PHOLEDs, triplet energies among various hole-transport and electron transporting materials were investigated. As presented in the following, the highly efficient green PHOLEDs with 3\% doping rate in CTP host and $\operatorname{Ir}(\text { ppy })_{3}$ dopant were demonstrated. Maximum current efficiency and EQE of $56.89 \mathrm{~cd} / \mathrm{A}$ and $18.0 \%$ are obtained with a triplet exciton confinement configuration using a narrow band-gap CTP host and high triplet energy charge transporting layers. Such a high efficiency is attributed to a good triplet exciton confinement effect by the narrow band-gap CTP host, improvement of self-quenching issues of singlet and triplet excitons by reducing the doping concentration, and introduction of good triplet exciton blocking layers at the EML interfaces.
To investigate triplet exciton confinement ability, five devices were designed as follows:

\author{
Device A: ITO/NPB $(40 \mathrm{~nm}) / \mathrm{CTP}: \operatorname{Ir}(\text { ppy })_{3}(8 \mathrm{wt} \%$, \\ $30 \mathrm{~nm}) / \mathrm{BAlq}(5 \mathrm{~nm}) / \mathrm{Alq}_{3}(20 \mathrm{~nm}) / \mathrm{LiF}(0.5 \mathrm{~nm}) / \mathrm{Al}$ \\ $(100 \mathrm{~nm})$; \\ Device B: ITO/NPB (30 nm)/TCTA (10 nm)/ \\ CTP : $\operatorname{Ir}(\text { ppy })_{3}(8 \mathrm{wt} \%, 30 \mathrm{~nm}) /$ Bphen $(25 \mathrm{~nm}) / \mathrm{LiF}$ \\ $(0.5 \mathrm{~nm}) / \mathrm{Al}(100 \mathrm{~nm})$; \\ Device C: ITO/NPB $(30 \mathrm{~nm}) / \mathrm{TCTA}(10 \mathrm{~nm}) /$ \\ CTP : $\operatorname{Ir}(\text { ppy })_{3}(5 \mathrm{wt} \%, 30 \mathrm{~nm}) /$ Bphen $(25 \mathrm{~nm}) / \mathrm{LiF}$ \\ $(0.5 \mathrm{~nm}) / \mathrm{Al}(100 \mathrm{~nm})$; \\ Device D: ITO/NPB (30 nm)/TCTA (10 nm)/ \\ CTP : $\operatorname{Ir}(\text { ppy })_{3}(3 \mathrm{wt} \%, 30 \mathrm{~nm}) /$ Bphen $(25 \mathrm{~nm}) / \mathrm{LiF}$ \\ $(0.5 \mathrm{~nm}) / \mathrm{Al}(100 \mathrm{~nm})$; \\ Device E: ITO/NPB (30 nm)/TCTA (10 nm)/ \\ CTP : $\operatorname{Ir}(\text { ppy })_{3}(1 \mathrm{wt} \%, 30 \mathrm{~nm}) /$ Bphen $(25 \mathrm{~nm}) / \mathrm{LiF}$ \\ $(0.5 \mathrm{~nm}) / \mathrm{Al}(100 \mathrm{~nm})$.
}

Where $\alpha$-NPB, TCTA, BPhen, and BAlq are $\mathrm{N}, \mathrm{N}^{\prime}-$ Bis(naphthalene-1-yl)-N,N'-bis(phenyl)benzidine), 4, $4^{\prime}, 4^{\prime \prime}$ tris(N-carbazolyl)-triphenylamine), 4,7-diphenyl-1, 10-phenanthroline, and aluminum (III) bis(2-methyl-8-quinolinato)-4- phenylphenolate, respectively.

Device A was fabricated with a structure to be the reference sample. Device B was made with a triplet exciton confinement structure. $J-V-L$ characteristics were measured over a brightness of $10,000 \mathrm{~cd} / \mathrm{m}^{2}$ and are displayed in Figure 3. For Device A we obtain at a brightness of $1000 \mathrm{~cd} / \mathrm{m}^{2}$ a driving voltage of $6.5 \mathrm{~V}$, the current and power efficiencies are $21.93 \mathrm{~cd} / \mathrm{A}$ and $10.82 \mathrm{~lm} / \mathrm{W}$. In Device B, the lower driving voltage of $4.7 \mathrm{~V}$ was measured due to the resistance reduction of CTP through good carrier injection and displacement in a narrow band-gap host as well as the good electron transporting properties of Bphen. CTP had been reported to be a good triplet green host and its exchange of energy (from $S_{1}$ to $T_{1}$ ) is as small as 0.3 to $0.5 \mathrm{eV}$ [48]. As expected, Device B shows good current and power efficiencies of, respectively, $39.81 \mathrm{~cd} / \mathrm{A}$ and $27.19 \mathrm{~lm} / \mathrm{W}$ at a brightness of $1000 \mathrm{~cd} / \mathrm{m}^{2}$. Its performance is still not adequate when considering good triplet excitons confinement configuration in the EML. Very low current efficiency rolloff of $5 \%$ over the brightness of $10,000 \mathrm{~cd} / \mathrm{m}^{2}$ is observed in $8 \%$ doped CTP PhOLED. Deep hole trapping and shallow electron trapping in the wide band-gap host such as CBP and $\operatorname{Ir}(\mathrm{ppy})_{3}$ dopant system have been already reported by other groups $[46,49]$. The $\mathrm{HOMO}$ of $\operatorname{Ir}(\mathrm{ppy})_{3}(5.3 \mathrm{eV})$ forms deep traps for holes in the host, governing the transport of holes in the EML. At high doping concentration, the emission zone is spread out in such a deep hole trapping device. Consequently, the selection of suitable host candidate with reasonable doping concentration is a critical issue to achieve high efficiency PHOLEDs as proven in reference [33]. Considering low roll-off characteristics in our devices, self-exciton quenching and triplet-triplet annihilation may be of high importance due to high doping concentration. To substantiate our argument, the doping concentration of Device B is varied to improve the triplet exciton confinement. 




FIgURE 3: $J-V-L$ and efficiency characteristics of Devices A and B.

Several PHOLEDs with $\operatorname{Ir}(\text { ppy })_{3}$ doping concentrations of $5 \%, 3 \%$, and $1 \%$ were fabricated with the Device $\mathrm{B}$ structure. These devices are designated as Device C (5\%), D $(3 \%)$, and $\mathrm{E}(1 \%)$. Figure 3 shows the $J-V-L$ characteristics of fabricated green phosphorescent devices. The $J-V$ characteristics with decreasing doping concentration from $5 \%$ to $1 \%$ have significantly increased the resistance to current conduction. The current densities at $5.0 \mathrm{~V}$ are $3.80 \mathrm{~mA} / \mathrm{cm}^{2}$, $1.40 \mathrm{~mA} / \mathrm{cm}^{2}$, and $0.63 \mathrm{~mA} / \mathrm{cm}^{2}$ for, respectively, the $5 \%, 3 \%$, and $1 \%$ doped devices (Device C, D, and E, resp.). The driving voltages for Device C, D, and E to reach $1000 \mathrm{~cd} / \mathrm{m}^{2}$ are, respectively, 4.7, 5.1, and 5.4 V (Figure 4). Improvement of $J-V$ characteristics with increasing doping concentration is a well-known phenomenon, as well as the origin of luminescence from trapped charges by dopant molecules [46]. In fact, the $\operatorname{Ir}(\mathrm{ppy})_{3}$ dopant and CTP host have, respectively, their HOMO energy levels at 5.3 and $5.7 \mathrm{eV}$, hence a gap of $0.4 \mathrm{eV}$ leads to a hole trapping in our devices. At a given constant brightness of $1000 \mathrm{~cd} / \mathrm{m}^{2}$, the current and power efficiencies are $49.14 \mathrm{~cd} / \mathrm{A}$ and $32.16 \mathrm{~lm} / \mathrm{W}$ for Device C, $55.76 \mathrm{~cd} / \mathrm{A}$ and $33.68 \mathrm{~lm} / \mathrm{W}$ for Device D, and $50.90 \mathrm{~cd} / \mathrm{A}$ and $29.61 \mathrm{~lm} / \mathrm{W}$ for Device E. The maximum current efficiency and EQE of $49.14 \mathrm{~cd} / \mathrm{A}$ and $15.5 \%$ for Device C, $56.89 \mathrm{~cd} / \mathrm{A}$ and $18.0 \%$ for Device D, and $51.56 \mathrm{~cd} / \mathrm{A}$ and $16.3 \%$ for Device E were obtained. The current efficiency of device E is improved by a factor of 1.4 compared to Device B.

\section{Charge Trapping}

Electroluminescence in PhOLEDs, as described previously, comes either from the energy transfer from the host to the guest molecules or from the charge trapping by the guest molecules. In the energy transfer model, the light emission by the dopant is due to the energy transfer from the excited host to the dopant $[30,50,51]$. The exciton is formed in the host material before being transferred to the dopant. Charge trapping has been studied from the beginning of models in the field of organic semiconductor based devices; it affects the device performance in OLEDs, organic thin film

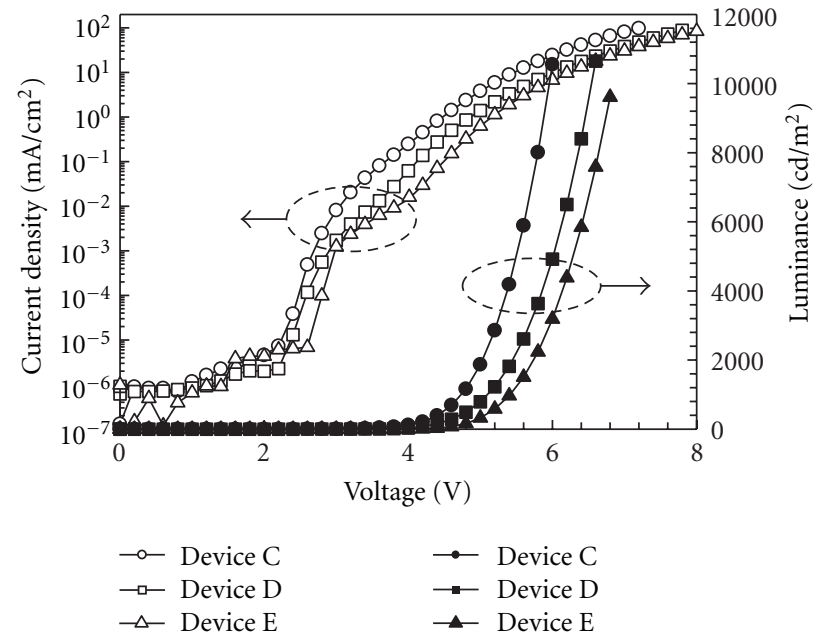

Figure 4: $J-V-L$ and efficiency characteristics of Devices C, D, and E.

transistors, and organic photovoltaic cells. In the emission by charge trapping, the direct recombination of electrons and holes occurs on guest molecules, and their trapping can significantly influence the external electroluminescence quantum efficiency. The essential requirement for carrier trapping is that the guest dopant must have a higher HOMO and a lower LUMO energy than that of the host material [52]. The charge trapping mechanism will also be observed when there is a large energy barrier for charge injection from charge transport layer to the host material.

Charge trapping model assumes that the dopant acts as a trap site which can capture a charged carrier [30, 5355]. The trapped charge recombines with a charge carrier of opposite sign to form an exciton which can contribute to light emission. In this mechanism charge carriers are directly trapped at dopant sites and the dopant is the center for the recombination and emission.

Charge trapping within the dopant material can be explained by the distribution of dopant molecules within the host. When a low concentration of the dopant in host matrix is used, the mobility limitation of a charge from one dopant site to another will lead a higher driving voltage [30]. If for example the host is $\mathrm{n}$ type material, as $4,4^{\prime}-$ $\mathrm{N}, \mathrm{N}^{\prime}$-dicarbazolebiphenyl (CBP), and the dopant material $\operatorname{Ir}(\mathrm{ppy})_{3}$ which is a p-type molecule, holes hop among the $\operatorname{Ir}(\mathrm{ppy})_{3}$ molecules in the CBP EML. With the low doping concentration, the distance between the $\operatorname{Ir}(\mathrm{ppy})_{3}$ molecules is large and appears to be a hole trap. In such a situation, the hole trapping limits additional hole injection which results in the increase of the driving voltage. However, when the doping concentration increases, the hole mobility increases since the distance between the $\operatorname{Ir}(\mathrm{ppy})_{3}$ molecules decreases. Such a transport characteristic effectively decreases the driving voltage.

The two light emission mechanisms in PhOLEDs are different in that the exciton formation center is the dopant molecule in the case the charge trapping model and the host molecule for the energy transfer model. Both mechanisms 


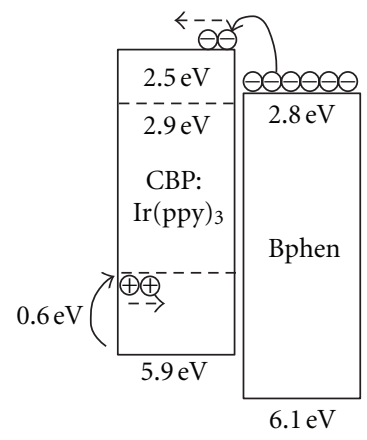

(a)

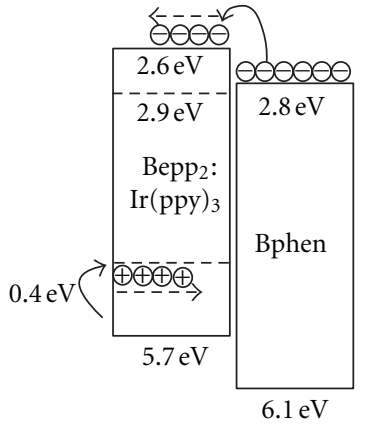

(b)
FIGURE 5: Energy level diagrams of CBP: $\operatorname{Ir}(\mathrm{ppy})_{3}$ (a) and Bepp $_{2}: \operatorname{Ir}(\mathrm{ppy})_{3}$ PHOLEDs (b).

contribute to the light emission in a certain rate depending on the device structure and energy levels of the organic materials in the PhOLED.

Charge trapping in PhOLEDs can be investigated by changing the concentration of the phosphorescent emitting material in the emissive layer and its dependence with the driving voltage can be studied. Charge trapping can be shallow or deep and it can be selective as concerning only electrons or only holes. In fact charge traps can be divided in two categories described as shallow traps and deep traps. The shallow traps can be activated and carried in the electric current by tunneling thermally activated or by hopping. Localized electronic states called deep traps are too deep to be thermally activated into current carrying states, they are effectively static. The presence of fixed charges modifies the electrostatic landscape of the material and leads to changes in electrons and holes recombination efficiency in OLEDs. It can as well improve the brightness of the device as it contributes to the electroluminescence, but it can be a disadvantage as it enhances the driving voltage [30].

4.1. Charge Trapping in Green PhOLED. These above arguments have been confirmed by our group in different studies such as the effect of hole trapping in green PhOLEDs using $\operatorname{Ir}(\mathrm{ppy})_{3}$ green emitter in two different host matrices CBP and $\mathrm{Bepp}_{2}$ (bis[2-(2-hydroxyphenyl)-pyridine]beryllium) [30] as represented, Figure 5. We fabricated PHOLEDs with the following structure: ITO/NPB $(30 \mathrm{~nm}) / \mathrm{TCTA}(10 \mathrm{~nm})$ Bepp $_{2}: \operatorname{Ir}(\text { ppy })_{3}$, or CBP : $(30 \mathrm{~nm}): \operatorname{Ir}(\text { ppy })_{3} /$ Bphen $(25 \mathrm{~nm}) /$ $\mathrm{LiF}(5 \mathrm{~nm}) / \mathrm{Al}(100 \mathrm{~nm})$.

We have realized the host-guest system to optimize the performance of green PHOLEDs based on a comparison between two host materials with different energy gaps: CBP and $\mathrm{Bepp}_{2}$. The minimization of hole trapping on the guest molecules and reduction of self-quenching or triplet-triplet annihilation are key factors to achieve the high efficiency. When compared with the wide band gap CBP, using a narrow band gap host $\left(\right.$ Bepp $\left._{2}\right)$ and green phosphorescent $\operatorname{Ir}(\mathrm{ppy})_{3}$ metal complex guest concentration as low as $2 \%$, the current and power efficiencies of $62.5 \mathrm{~cd} / \mathrm{A}$ (EQE 19.8\%) and $51.0 \mathrm{~lm} / \mathrm{W}$, respectively, and a low current efficiency rolloff value of $10 \%$ over the brightness of $10,000 \mathrm{~cd} / \mathrm{m}^{2}$ were

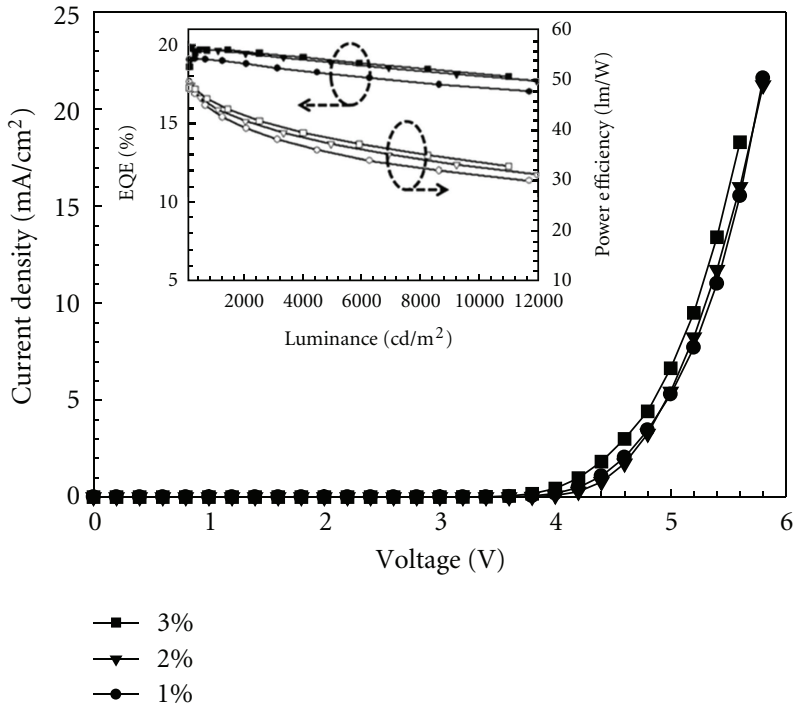

Figure 6: $J-V$ characteristics of fabricated $\mathrm{Bepp}_{2}: \operatorname{Ir}(\mathrm{ppy})_{3}$ green PHOLEDs with doping concentration from 1 to $3 \%$. Inset shows the EQE and power efficiency as a function of luminance.

demonstrated in this Bepp 2 single-host system (see Figure 6). We have limited the charge trapping by the use of an ideal host-guest device structure to produce a high efficiency phosphorescent device by minimizing hole trapping on the guest molecules and reducing self-quenching or triplettriplet annihilation. The device structure to optimize the high current efficiencies, low current roll-off, high color stability, and low doping conditions has been explored.

To corroborate further our hypothesis of shallow hole trapping at the phosphorescent molecules in the emitting layer, we performed the capacitance measurements as a function of applied voltages in a $3 \% \operatorname{Ir}(\text { ppy })_{3}$ doped in the Bepp $_{2}$ and CBP devices. A constant dc bias ranging from $0 \mathrm{~V}$ to $10 \mathrm{~V}$ was superimposed on the ac bias. Figure 7 shows the capacitance variation normalized to the geometrical capacitance $\left(C_{0}\right)$ with the applied dc voltage. As seen from Figure 7, the capacitance of doped and undoped devices increases in forward bias, reaches a maximum value, and then decreases. Onset of the increase depends on the host material. This result suggests that the increase of capacitance may be dependent on the capacity of holding charges in the emitting layer. At zero bias, the capacitance of all devices is the same as the geometrical capacitance. On applying a small forward bias, no change in capacitance is observed and it remains equal to $C_{0}$. It starts increasing when the hole injection begins from the anode and reaches a maximum point due to the accumulation of hole charges. On further increase of bias voltage, the minority charge carriers injection occur, resulting in a recombination of holes and electron in the emitting layer and subsequently the emission of light.

Early occurrence of recombination as observed in a Bepp $_{2}: \operatorname{Ir}(\text { ppy })_{3}$ device indicates that the hole trapping in the Bepp $_{2}$ host is not a serious issue when compared to that of CBP : $\operatorname{Ir}(\mathrm{ppy})_{3}$ and this cannot be attributed to the electron mobility in $\mathrm{Bepp}_{2}$ (about $10^{-4} \mathrm{~cm}^{2} / \mathrm{Vs}$ ) and CBP materials 


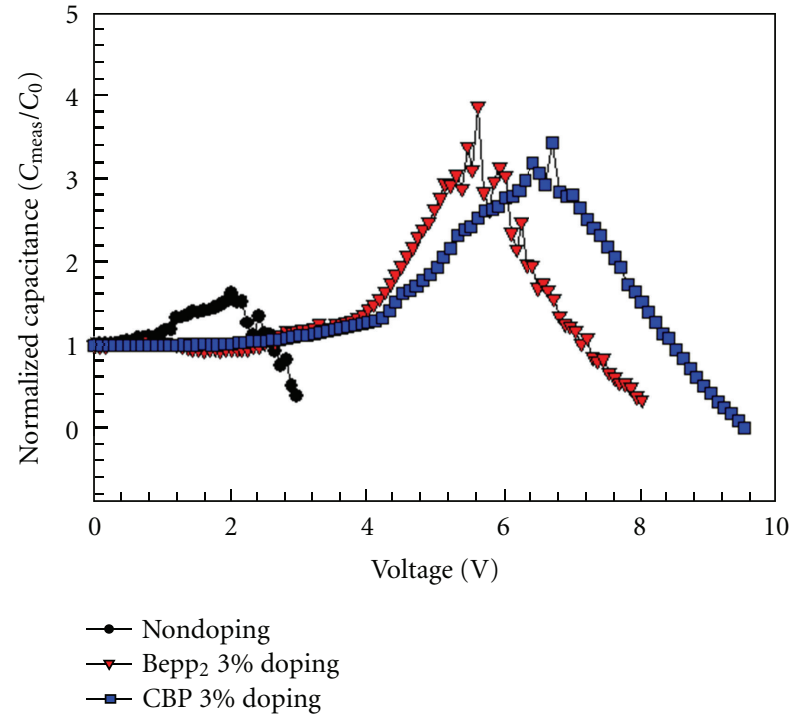

FIGURE 7: Capacitance variation normalized to geometrical capacitance $\left(C_{0}\right)$ with the applied dc voltage.

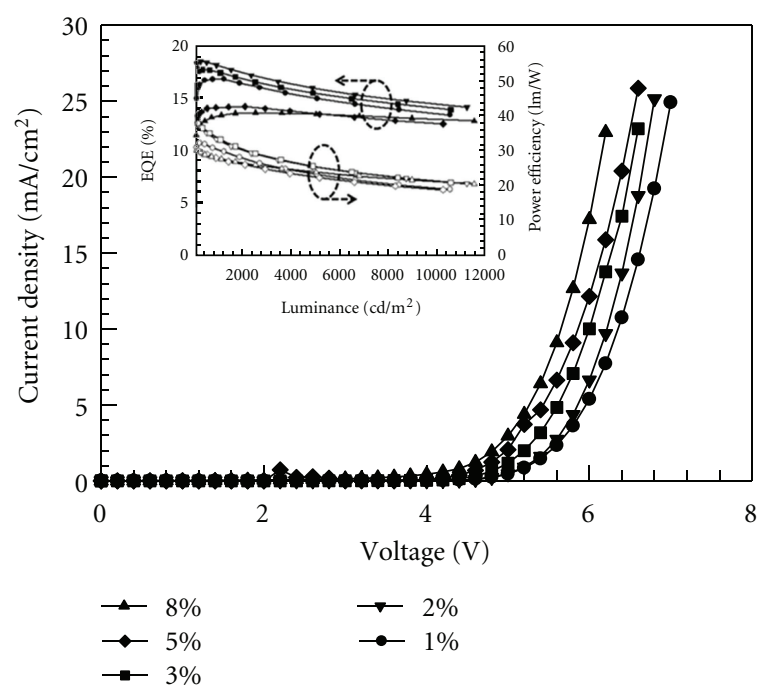

Figure 8: $J-V$ characteristics of CBP $: \operatorname{Ir}(\mathrm{ppy})_{3}$ green PHOLEDs with doping concentration from 1 to $8 \%$. Inset shows the EQE and power efficiency as a function of luminance.

(about $3 \times 10^{-4} \mathrm{~cm}^{2} / \mathrm{Vs}$ ). The shallow traps for hole charge carriers which facilitate its transport may be responsible for the early recombination of electron and hole carriers in $\mathrm{Bepp}_{2}: \operatorname{Ir}(\mathrm{ppy})_{3}$ device.

Ideal host-guest device structures produce a high efficiency phosphorescent device minimizing the hole trapping on the guest molecules and reducing the self-quenching or triplet-triplet annihilation. The device structure to optimize the high current efficiencies, low current roll-off, high color stability, and low doping conditions has been explored. The doping concentration was varied from 1 to $8 \%$. The $J-V$ characteristics (Figure 8) show a strong dependence on the dopant concentration.
The strong dependence of $J-V$ characteristics on the dopant concentration is the consequence of the fact that the phosphorescent green emission is strongly dependent on the hole trapping at the phosphorescent guest molecules level. The deep hole trapping and the shallow electron trapping in the CBP host and $\operatorname{Ir}(\mathrm{ppy})_{3}$ dopant system were reported earlier by other groups $[26,29]$. The HOMO of Ir (ppy) 3 $(5.3 \mathrm{eV})$ forms the deep traps for the holes in the CBP host $(\mathrm{HOMO}=5.9 \mathrm{eV})$, governing the transport of holes in the emitting layer. Further, the strong $510 \mathrm{~nm}$ green $\operatorname{Ir}(\text { ppy })_{3}$ emission peak (CIE $(\mathrm{x}, \mathrm{y})$ coordinates at $1000 \mathrm{~cd} / \mathrm{m}^{2}$ are $(0.29$ to $0.31,0.60))$ and a weak emission at about $450 \mathrm{~nm}$ due to the CBP host appear at a concentration below $5 \%$. Upon enhancing the dopant concentration, the CBP host emission completely disappeared. Even if the better device performance appears at the low doping concentration, the high roll-off and the emission from the host in the EL output are attributed to the too narrow emission zone by deep hole trapping in the CBP host. The emission zone is spread out with a high doping concentration in such deep hole trapping devices. Consequently, the selection of the suitable host candidates is a critical issue to achieve the high efficiency PHOLEDs.

4.2. Minimization of Charge Trapping in Red PhOLEDs. In this section, we present the minimization of charge trapping in red PhOLEDs by a good energy level match between the host and guest. Förster and/or Dexter energy transfer processes [56] between host and guest molecules play an important role in confining the triplet energy excitons in the phosphorescent guest. This determines the triplet state emission efficiency in PHOLEDs. Förster energy transfer [57] is a long range interaction (up to $10 \mathrm{~nm}$ ) due to dipoledipole coupling of donor host and acceptor guest molecules, while Dexter energy transfer [58] is a short-range process (typically $1-3 \mathrm{~nm}$ ) which requires overlapping of orbitals of adjacent molecules. The phosphorescence emission in the conventional host-guest phosphorescent system occurs either with Förster transfer from the excited singlet $S_{1}$ state of the host to the excited singlet $S_{1}$ state of the guest and Dexter transfer from the triplet $T_{1}$ state of the host to the triplet $\mathrm{T}_{1}$ state of the guest or direct exciton formation on the phosphorescent guest molecules, resulting in a reasonable good efficiency.

In the following, we demonstrate that to achieve high efficiency PhOLEDs a good confinement of the triplet exciton of phosphorescent dopant is needed with the use of an appropriate triplet energy gap host. Such a combination host-guest will result in an efficient radiative decay in the dopant. We illustrate this principle comparing first the efficiency of the same red emitter tris(1phenylisoquinoline)iridium $\left(\operatorname{Ir}(\text { piq })_{3}\right)$ in a CBP matrix or in Bebq $_{2}$ (bis(10-hydroxybenzo [h] quinolinato)beryllium) matrix, the CBP band gap being wider than $\mathrm{Bebq}_{2}$ band gap. Second, the same host $\mathrm{Bebq}_{2}$ is doped with $\operatorname{Ir}(\mathrm{phq})_{2}$ (acac) (iridium (III) bis(2-phenylquinoline) acetylacetonate) that has a narrower gap than $\operatorname{Ir}(\text { piq) })_{3}$ (Figures 9 and 10). 


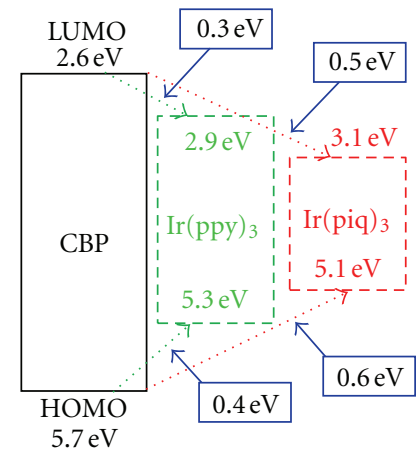

FIGURE 9: Energy level diagram of the $\operatorname{Ir}(\mathrm{ppy})_{3}$ green and $\operatorname{Ir}(\mathrm{piq})_{3}$ red phosphorescent complex doped by the CBP host.

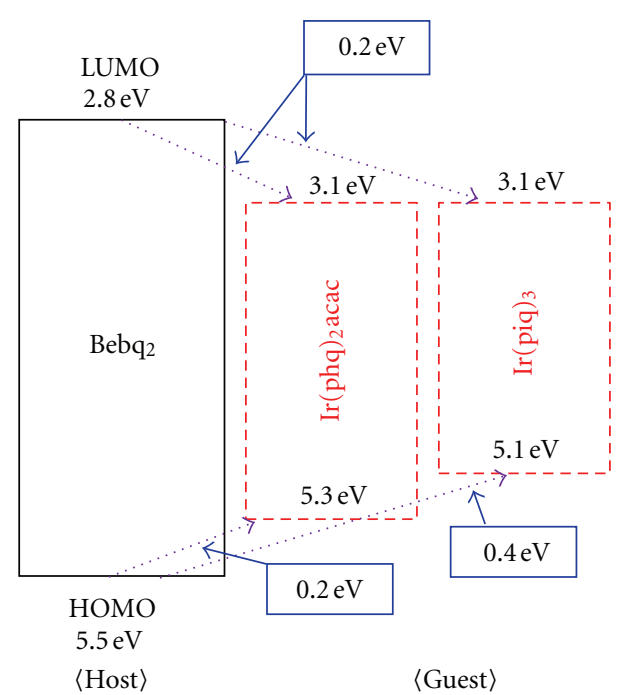

Figure 10: Energy level diagram of the $\mathrm{Bebq}_{2}$ fluorescent host and $\operatorname{Ir}(\mathrm{phq})_{2}$ acac and $\operatorname{Ir}(\mathrm{piq})_{3}$ red phosphorescent dopant materials.

Figure 9 shows the energy level diagram of the $\operatorname{Ir}(\mathrm{piq})_{3}$ red phosphorescent complexes used in doping the CBP host while Figure 10 shows the energy diagrams for both $\operatorname{Ir}(\text { piq })_{3}$ and $\operatorname{Ir}(\mathrm{phq})_{2}$ (acac) in $\mathrm{Bebq}_{2}$ matrix. However, the wide band-gap host and narrow gap guest system often causes an increase in the driving voltage due to the difference in HOMO and/or LUMO levels between the guest and host materials [59]. Thus, the guest molecules are thought to act as deep trapping centers for electrons and holes in the emitting layer, causing an increase in the driving voltage of the PHOLED. The dopant concentration in such a hostguest system is usually as high as about $6-10 \%$ because injected charges should move through guest molecules in the emitting layer. Therefore, self-quenching or triplet-triplet annihilation by guest molecules is an inevitable problem in host-guest systems with high doping concentrations. Earlier, Kawamura et al. had reported that the phosphorescence photoluminescence quantum efficiency of $\operatorname{Ir}(\mathrm{ppy})_{3}$ could be decreased by $5 \%$ with an increase in the doping concentration from $2 \%$ to $6 \%$ [47]. Consequently, the selection of suitable host candidates is a critical issue when fabricating high efficiency PHOLEDs.

We demonstrate the importance of exciton confinement in the efficiency of a PhOLED based on the energy difference between the host matrix and the guest molecules for the same phosphorescent emitter. A narrower band gap host will result in a higher efficiency PhOLED. In this study, the minimized charge trapped host-guest system is investigated by using a narrow band-gap fluorescent host material in order to address device performance and manufacturing constraints. Here, we report an ideal host-guest system that requires only $1 \%$ guest doping weight for a good energy transfer and provides ideal quantum efficiency in PHOLEDs. We also report that strong fluorescent host materials function very well in phosphorescent OLEDs.

PhOLEDs operation can be explained based on efficient Förster energy transfers from the host singlet state to the guest singlet and triplet mixing state which appears to be the key mechanism for phosphorescence emission.

Indeed, such an enhanced performance of the Bebq $_{2}: \operatorname{Ir}(\mathrm{phq})_{2}$ acac PHOLEDs was not expected with an extraordinary low doping concentration (1\%) by contrast with most phosphorescent devices (6-10\%). In order to investigate the origin for the enhanced performance, we fabricated several PHOLEDs by varying the doping concentration from $0.5 \%$ to $2 \%$ in the host-guest system. Current and luminance evolutions as a function of voltage are presented in Figure 11. These data provide evidence for: (1) complete energy transfer from the fluorescent host to phosphorescent guest, except at extremely low doping concentrations $(0.5 \%)$; (2) no significant difference between measured $I-V$ characteristics for identical devices but with different dopant concentrations ranging between 0.5 and $2 \%$; (3) the quenching of both luminance, and current and power efficiencies with higher doping concentrations (2\%).

Therefore, a highly efficient simple bilayer PHOLED structure with a $\operatorname{Ir}(\mathrm{phq})_{2}$ acac guest doping concentration as low as $1 \%$ in the narrow band-gap Bebq 2 fluorescent host was demonstrated for the first time by our group.

To understand the phosphorescence emission mechanism more precisely in the $\mathrm{Bebq}_{2}: \operatorname{Ir}(\mathrm{phq})_{2}$ acac host-guest system, we fabricated and studied a series of PHOLEDs. First, we used the well-known wide band-gap CBP host material instead of $\mathrm{Bebq}_{2}$ and fabricated the device with a structure: NPB $(40 \mathrm{~nm}) / \mathrm{CBP}: \operatorname{Ir}(\mathrm{phq})_{2}$ acac $(30 \mathrm{~nm}, 10 \%) / \mathrm{BAlq}$ $(5 \mathrm{~nm}) / \mathrm{Alq}_{3}(20 \mathrm{~nm}) / \mathrm{LiF}(0.5 \mathrm{~nm}) / \mathrm{Al}(100 \mathrm{~nm})$. At a luminance of $1000 \mathrm{~cd} / \mathrm{m}^{2}$ the resultant operating voltage was $7.1 \mathrm{~V}$ with current and power efficiencies of $14.41 \mathrm{~cd} / \mathrm{A}$ and $6.28 \mathrm{~lm} / \mathrm{W}$, and an EQE of $11.5 \%$. Furthermore, the maximum current and power efficiencies were $14.43 \mathrm{~cd} / \mathrm{A}$ and $8.99 \mathrm{~lm} / \mathrm{W}$.

Obviously, the two fold increase in the driving voltage is a consequence of the deep trapping of injected holes and electrons at $\operatorname{Ir}(\mathrm{phq})_{2}$ acac sites in the CBP : $\operatorname{Ir}(\mathrm{phq})_{2}$ acac system. Direct charge trapping at the $\operatorname{Ir}(\mathrm{phq})_{2}$ acac guest 


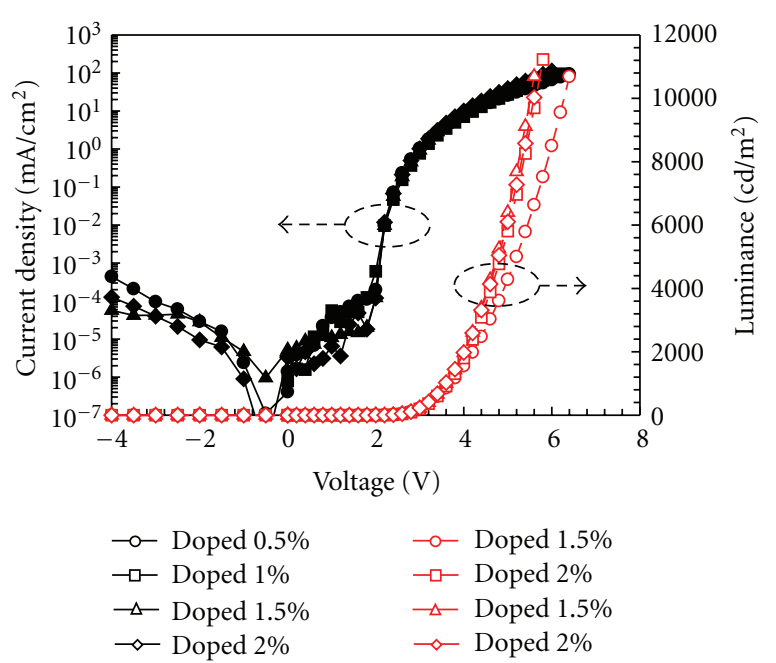

Figure 11: $J-V-L$ plot of red PHOLEDs doped with different concentrations (0.5-2\%) of $\operatorname{Ir}(\mathrm{phq})_{2} \mathrm{acac}$ in $\mathrm{Bebq}_{2}$.

molecules seems to be the key mechanism for phosphorescence emission in this host-guest system.

To corroborate our experimental results further, a PHOLED was fabricated using $\operatorname{Ir}(\text { piq })_{3}$ red emitting phosphorescent doping instead of $\operatorname{Ir}(\mathrm{phq})_{2} \mathrm{acac}$ and a $\mathrm{Bebq}_{2}$ host. The fabricated device was: DNTPD $\left(N, N^{\prime}-\right.$ diphenyl- $N, N^{\prime}$-bis-[4-(phenyl-m-tolylamino)-phenyl]-biphenyl-4,4'-diamine) $(40 \mathrm{~nm}) / \mathrm{Bebq}_{2}: \operatorname{Ir}(\text { piq })_{3}(50 \mathrm{~nm}, 4 \%) /$ $\mathrm{LiF}(0.5 \mathrm{~nm}) / \mathrm{Al}(100 \mathrm{~nm})$. A weak emission peak at $500 \mathrm{~nm}$ in the electroluminescence spectra due to the $\mathrm{Bebq}_{2}$ host arises at a doping concentration of $4 \%$ (significantly high by comparison with an $\operatorname{Ir}(\mathrm{phq})_{2}$ acac doping concentration $0.5 \%$ ), accompanied by a strong peak at $620 \mathrm{~nm}$ due to an $\operatorname{Ir}(\mathrm{piq})_{3}$ doping molecule. At luminance of $1000 \mathrm{~cd} / \mathrm{m}^{2}$, the corresponding operating voltage, current and power efficiencies were $3.5 \mathrm{~V}, 8.41 \mathrm{~cd} / \mathrm{A}$, and $7.34 \mathrm{~lm} / \mathrm{W}$. Furthermore, the maximum current and power efficiency values were $9.38 \mathrm{~cd} / \mathrm{A}$ and $11.72 \mathrm{~lm} / \mathrm{W}$. Increasing the $\operatorname{Ir}(\mathrm{piq})_{3}$ concentration to $6 \%$ suppresses the $\mathrm{Bebq}_{2}$ host emission and results in a clean electroluminescence red emitting peak at $620 \mathrm{~nm}$ due to the $\operatorname{Ir}(\mathrm{piq})_{3}$ doping molecules. However, the device performance deteriorates with increasing doping concentration due to the self-quenching.

\section{Ideal Doping Concentration}

In PhOLEDs the triplet-triplet energy transfer between host and dopant molecules is explained based on Dexter mechanism $[21,60,61]$ which is a short-range intermolecular interaction involving wave functions overlap $[26,62]$; it takes place within about $1 \mathrm{~nm}$ range $[63,64]$. This imposes constraints in the distribution and concentration of the dopant molecules within the host matrix. Among the conditions for good efficiency is the fact that every host molecule in an excited state will need to have a guest molecule in a range close enough to receive this excitation energy and radiate it back in form of phosphorescent light $[65,66]$. This doping concentration can be idealized for any system, but among PhOLEDs of a given color, it is necessary to first of all maximize the exciton confinement and minimize the charge trapping by minimizing the energy gap between the host and guest HOMOs and LUMOs $[67,68]$ as presented earlier in this paper. The ideal doping concentration should minimize charge trapping, self-quenching and triplet-triplet annihilation $[67,69]$.

In this context, we have evaluated an ideal guest concentration in PhOLEDs and made an experimental comparison to support our predictions. We use a green PhOLED, for which we evaluate an ideal doping concentration of about $1.5 \%$.

We assume films with a crystalline structure. In order to have the most compact configuration we choose a disposition of molecules in face-centered cubic (fcc) organization. The host molecules are located at the vertexes of extended unit lattice containing $4 \times 4 \times 4$ host molecules. In such a structure we replace the excited host molecule located at the center by a dopant molecule. Obviously, this choice is not completely conform with the reality as the actual samples are rather amorphous. This will cause a certain discrepancy when comparing with experimental results. Nevertheless, this approach is valid because the molecular densities of the structures are equivalent and the size of host and guest molecules we will be using experimentally are comparable both for CBP or Bepp 2 as a host matrix when using $\operatorname{Ir}(\mathrm{ppy})_{3}$ as a green phosphorescent dopant, respectively, 8.67, 9.23, and $11.9 \AA$.

Our computation gave a molecular number corresponding to the constant molar fraction of $0.93 \mathrm{~mol} \%(1 / 107$ mole fraction) as an ideal Dexter transfer condition. From this assumption and consideration of molecular weight of host and dopant molecules, we could simply get an ideal doping concentration. As an actual experimental condition, we obtained $1.19 \%$ of doping concentration by changing 0.93 mole fraction to weight fraction for $\mathrm{CBP} / \operatorname{Ir}(\mathrm{ppy})_{3}$ system from this approach. However, there could be some discrepancy between this condition and experimental results because it assumed that the dopant molecules may have similar size to that of host molecules due to a small fraction of dopant molecules. Nevertheless, the prediction we obtained for the $\mathrm{CBP} / \operatorname{Ir}(\mathrm{ppy})_{3}$ system was very close to that obtained from the Kawamura's approach (1.02\%, [70]). This indicates that our lattice assumption is closely matched to a real amorphous film situation. Similarly, 1.93\% $(0.93 \mathrm{~mol} \%)$ of doping concentration was predicted in case of Bepp $2 / \operatorname{Ir}(\text { ppy })_{3}$ system.

This consideration lead us to estimate that in $1 \mathrm{D}$ picture two dopant molecules should be separated by two host molecules (Figure 12).

From simulations and experiments with 1D concept we obtain a good PhOLEDs performance with a doping concentration as low as $1 \%$. This is the reason why we assumed the molecular arrangement described above.

For the verification of our assumptions, we conducted a series of experiments varying the doping concentration in the emissive layer. The strong green light emission at $510 \mathrm{~nm}$ for all electroluminescence curves is attributed to the 


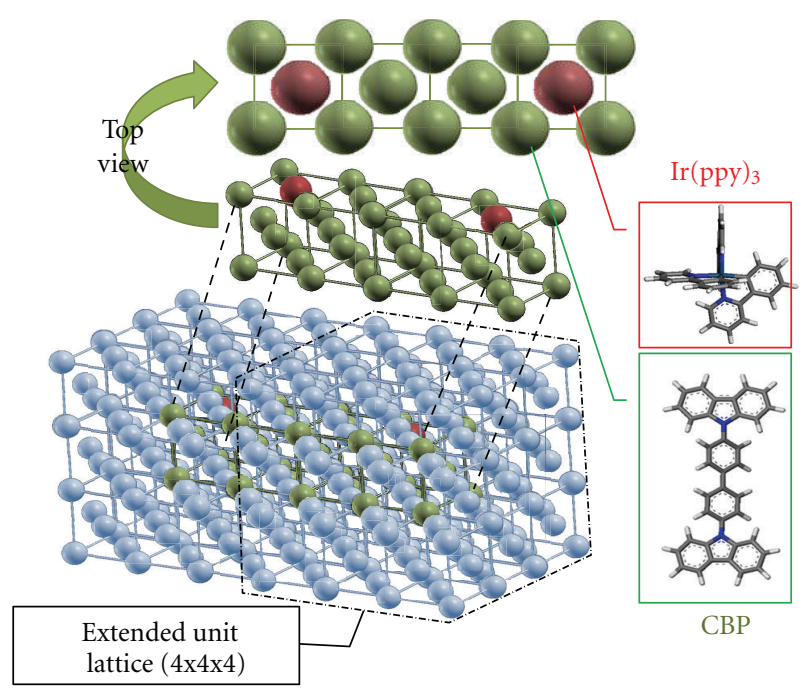

FIGURE 12: Imaginary molecular arrangements assuming a cubic lattice which is filled by imaginary spherical molecules as an fcc arrangement.

phosphorescence of $\operatorname{Ir}(\mathrm{ppy})_{3}$. In principle, we can detect the side emission from the host material if the energy transfer is incomplete or inefficient. We observed that the host emission (at $420 \mathrm{~nm}-450 \mathrm{~nm}$ ) disappears at the expected ideal doping concentration of $1.0 \%$ when the EML thickness of CBP is $10 \mathrm{~nm}$. The doping concentration requirement for the elimination of CBP host emission (for complete energy transfer), however, increases when increasing the EML thickness; for instance, $3 \%$ for $20 \mathrm{~nm}$ and $5 \%$ for $30 \mathrm{~nm}$. The necessity of a higher doping concentration for a thicker EML condition is presumably due the large discrepancy of HOMO and LUMO levels between the CBP host and guest materials (Figure 13) which might give a deep trapping nature. The injected holes in the doped EML cannot move easily due to deep trapping in $\operatorname{Ir}(\mathrm{ppy})_{3}$ guest molecules and as a result an excess of charges will be located around the HLT/EML interface. Some electrons will be able to penetrate the HTL due to a relatively high electron mobility of doped EML. In such devices, a higher doping concentration is favorable to get high device performances as we reported previously [46].

However, such an overdoping is not necessary for thinner EML (about $10 \mathrm{~nm}$ ) because the countercharge carriers (the electrons) may be injected and transported earlier than holes. Thus, they are easily crowded at the HTL/EML interface because the difference of LUMO levels between CBP host and $\operatorname{Ir}\left(\right.$ ppy) ${ }_{3}$ guest is relatively small (about $0.4 \mathrm{eV}$ ), while the difference of HOMO levels of same system is larger (about $0.6 \mathrm{eV}$ ) [46]. Thus, holes carriers can recombine with electrons very early before the preliminary trapping process starts at the guest molecules. In other words, the probability of holes migration to the opposite side (toward cathode) is presumably weaker than that of electrons migration toward anode side. From these circumstances and results, we conclude that the ideal doping concentration of $\mathrm{CBP} / \mathrm{Ir}(\mathrm{ppy})_{3}$ system could be $1 \%$ to the exclusion of the

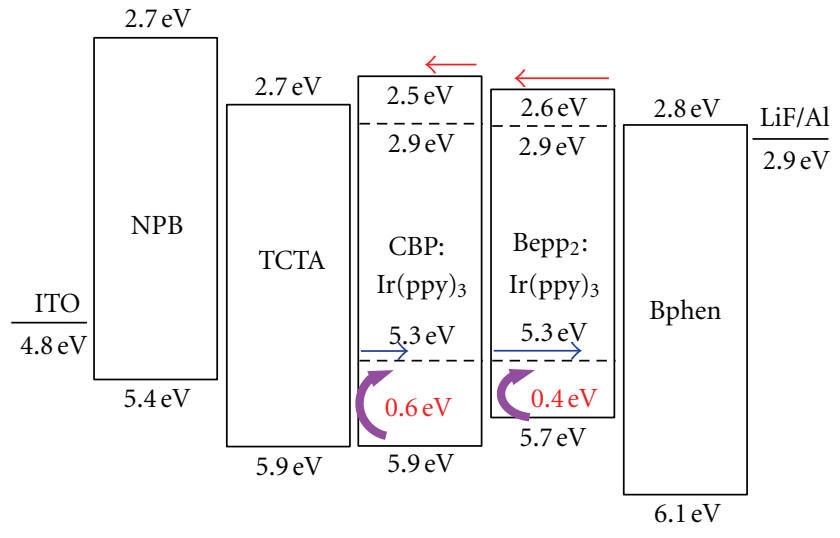

FIGURE 13: Energy band diagram of CBP : $\operatorname{Ir}(\text { ppy })_{3}$ and Bepp 2 : $\operatorname{Ir}(\text { ppy })_{3}$ based green PHOLEDs.

trapping processes. As a result, we come to a conclusion that the ideal doping ratio could be derived or predicted from the consideration of the molecular packing condition in extended unit lattice (the expected doping ratio of $\left.\mathrm{CBP} / \operatorname{Ir}(\text { ppy })_{3}: 1.19 \%\right)$. However, we observed the maximum EQE value at the slightly thicker, overdoped condition suggesting that $10 \mathrm{~nm}$ is too thin to confine most carriers at the EML region. It means that the ideal doping concentration for complete energy transfer could be somewhat different from that gives the maximum device efficiency.

Similarly, a relatively low doping concentration of about $1.93 \%$ was predicted for ideal and complete energy transfer in $\mathrm{Bepp}_{2} / \mathrm{Ir}(\mathrm{ppy})_{3}$. And this was confirmed by the EML spectra of Bepp $2 / \operatorname{Ir}(\text { ppy })_{3}$ as a function of EML thickness and doping ratio. Bepp $2 / \operatorname{Ir}(\mathrm{ppy})_{3}$ does not require an overdoping at the thicker EML condition; for instance $1.5 \%$ at $20 \mathrm{~nm}$, $2 \%$ at $30 \mathrm{~nm}$. The reason for a complete energy transfer at the relatively reduced doping ratio even in the thicker EML condition of $\mathrm{Bepp}_{2} / \mathrm{Ir}(\mathrm{ppy})_{3}$ is possibly due to the lower differences of LUMO levels and HOMO levels between host and guest molecules $(0.3$ to $0.4 \mathrm{eV})$. In other words the charge carriers may be spread out much more uniformly in all around EML regions because of no radiation of charge injection that provides good charge balancing in the EML layer. From such a situation showing relatively low energy barriers between HOMOs and LUMOs of host and guest molecules, we could obtain the ideal doping condition even at the normal thickness condition. As we recommended before, the discrepancy between the calculation and the experimental values might come from the assumptions of crystal lattice and molecular spheres, the slight difference of molecular sizes and so forth. Nevertheless, we achieved a very close approximation in the evaluation of an ideal doping concentration for PhOLEDs described by Dexter energy transfer.

From the extensive comparison of our devices, we conclude that the optimized condition for $\mathrm{CBP} / \mathrm{Ir}(\mathrm{ppy})_{3}$ is the $20 \mathrm{~nm}$ thickness and $3 \%$ doping concentration. In the other hand, only $1.5 \%$ doping concentration for the same thickness of $20 \mathrm{~nm}$ in the case of $\mathrm{Bepp}_{2} / \mathrm{Ir}(\mathrm{ppy})_{3}$, that shows a lower driving voltage and higher EQE. This difference 

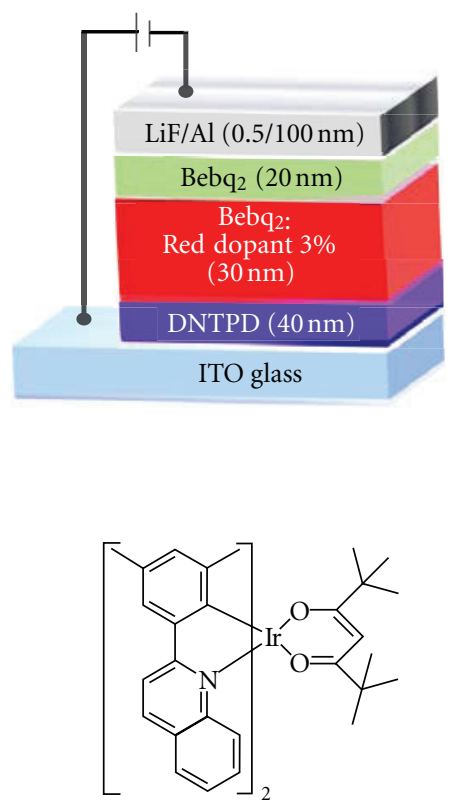

$\operatorname{Ir}(\mathrm{mphq})_{2}(\mathrm{tmd})$

(3)

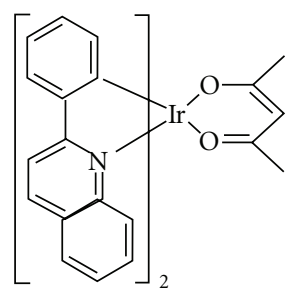

$\operatorname{Ir}(\mathrm{phq})_{2}(\mathrm{acac})$

(1)

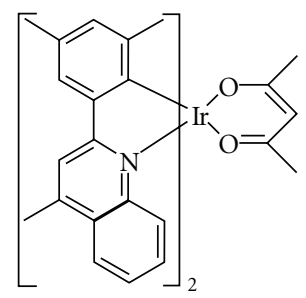

$\operatorname{Ir}(\mathrm{mphmq})_{2}(\mathrm{acac})$

(4)

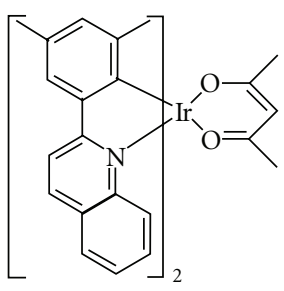

$\operatorname{Ir}(\mathrm{mphq})_{2}(\mathrm{acac})$

(2)

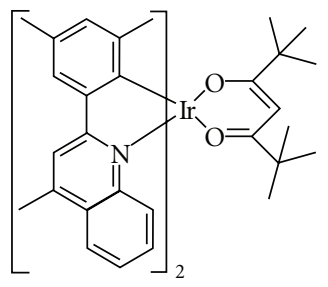

$\operatorname{Ir}(\mathrm{mphmq})_{2}(\mathrm{tmd})$

(5)

Figure 14: Schematic cross-section of red PHOLED with different complexes 1-5 and molecular structure of complexes 1-5.

reflects the fact that they are more delay processes such as charge trapping, nonradiative decay process, and triplettriplet annihilation in $\mathrm{CBP} / \operatorname{Ir}(\mathrm{ppy})_{3}$.

\section{PhOLED Materials}

We demonstrate the importance of material structure to ultimately affect the HOMO and LUMO positions in the dopant and consecutively affect the efficiency of the PhOLED [41]. We synthesized red emitters based on Ir complexes with successive modifications on the ligands. We report new red dopants with methylated phenyl ring and quinoline ring which are coordinated to the $\operatorname{Ir}(\mathrm{III})$ atom. Every dopant also has ancillary ligands, such as acetylacetonate (acac) and 2,2,6,6-tetrametylheptane-3,5-dionate (tmd) groups. The PHOLEDs prepared by these organometallic complexes showed very efficient and bright red phosphorescence with extremely high EQE up to $24.6 \%$ (in case of the dopant with methylated main ligand and a sterically crowded tmd ancillary ligand). The addition of an electrondonating methyl group to the metallated phenyl ring (mphq) gave a bathochromic shift (compare to a reference sample), while the additional introduction of methyl group to the quinoline ring (mphmq ligand) led to a hypsochromic shift compared to the spectral range of the mphq ligand as presented below. In addition, the change of ancillary ligand to a tmd moiety from an acac moiety results in significant improvement of device efficiency.

In this study, we prepared $\operatorname{Ir}(\mathrm{phq})_{2}$ (acac)-based red dopants having sterically crowded alkyl moieties on their main ligands as well as ancillary ligands. First, we added methyl groups on a phenyl part as well as a quinoline part of main lingand in $\operatorname{Ir}(\mathrm{phq})_{2}$ (acac) to increase intermolecular steric interaction to give reduced self-quenching effect. From this chemical modification, we could obtain very clear red spectra with much narrower full width at half-maximum. In addition, we also added sterically crowded ancillary ligand by using tert-butyl moiety to even protect the concentration quenching. The PHOLEDs containing those dopants as an emitter showed extremely high EQEs up to $24.6 \%$, which corresponds to an extremely high record as a red electrophosphorescent device to date.

For the device fabrication, for the reasons of efficiency presented earlier, we utilized a narrow bandgap fluorescent host material, $\mathrm{Bebq}_{2}$, to realize a highly efficient red PHOLEDs with excellent energy transfer [31, 71-77]. The exact device configuration used in this work was indium tin oxide (ITO)/DNTPD $(40 \mathrm{~nm}) / \mathrm{Bebq}_{2}$ : red dopants (3\%, $30 \mathrm{~nm}) / \mathrm{Bebq}_{2}(20 \mathrm{~nm}) / \mathrm{LiF}(0.5 \mathrm{~nm}) / \mathrm{Al}(100 \mathrm{~nm})$.

The device performances of the five different red PHOLEDs were investigated at the same doping concentration. The synthetic scheme and the chemical structures of those materials with formula $\operatorname{Ir}(\mathrm{phq})_{2}(\mathrm{acac})(1)$, (mphq) $)_{2} \operatorname{Ir}$ (acac) (2), (mphq) $)_{2} \operatorname{Ir}(\mathrm{tmd})$ (3), (mphmq) $\operatorname{Ir}(\mathrm{acac})$ (4), (mphmq) $)_{2} \operatorname{Ir}(\mathrm{tmd})$ (5), with (mphq) $=2-$ (3,5-dimethylphenyl) quinoline, $(\mathrm{acac})=$ acetylacetonate, $(\mathrm{tmd})=2,2,6,6$-tetrametylheptane-3,5-dionate, $(\mathrm{mphmq})=$ 2-(3,5-dimethylphenyl)-4-methylquinoline, are summarized in Figure 14 with the device structure. 

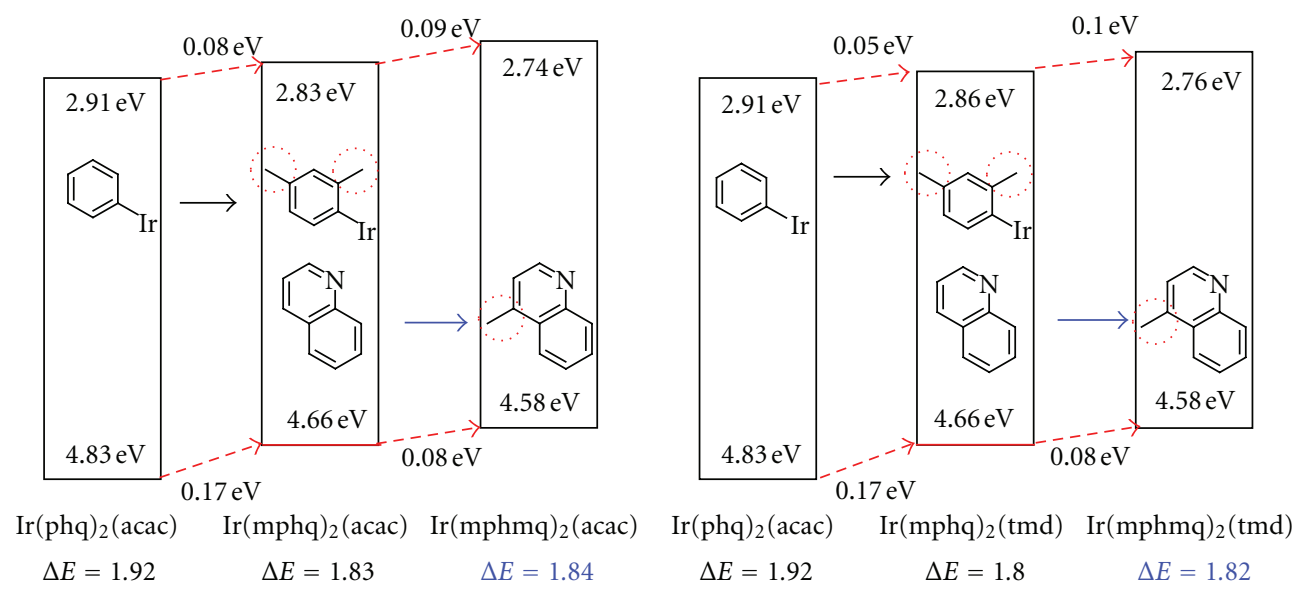

FIGURE 15: Energy band diagrams of complexes 1-5 from molecular simulation.

All five complexes show some vibronic bands in their emission spectra at $77 \mathrm{~K}$. The phosphorescence peak wavelength can be fine-tuned by substitution of the electrondonating or electron-withdrawing groups to the main ligand. In order to qualitatively understand the nature of the phosphorescent excited state of cyclometalated iridium complexes, we preliminarily executed a HOMO/LUMO calculation on $\operatorname{Ir}(\mathrm{phq})_{2}(\mathrm{acac})$. As a result, we found that the HOMO is distributed over the phenyl ring (3,5-position) and the iridium atom, while the LUMO is localized at the quinoline ring (4-position). Thus, the substitution of the electron-donating group $\left(-\mathrm{CH}_{3}\right)$ to the phenyl ring is expected to give a direct effect on lowering the HOMO level (stabilization of HOMO), which results in a reduction of the bandgap. The results obtained from the molecular simulation are summarized in Figure 15.

As a result, substitution of electron donating methyl group $\left(-\mathrm{CH}_{3}\right)$ for hydrogen in 3,5-position of phenyl chromophore of compound 1 leads to a 9-12 nm red shift, due the a destabilization of the d-orbital in the central $\operatorname{Ir}(\mathrm{III})$ atom from the change of this ligand-based excited state (compounds 2 and 3). Figure 16 shows the current densityvoltage $(J-V)$ characteristics of fabricated red PHOLEDs. At a constant voltage of $5.0 \mathrm{~V}$, current density values of $19.1,23.7,38.6,24.4$, and $27.9 \mathrm{~mA} / \mathrm{cm}^{2}$ are observed in the fabricated PHOLEDs A, B, C, D, and E, respectively. The driving voltage to reach $1000 \mathrm{~cd} / \mathrm{m}^{2}$ are $4.0,3.8,3.9,3.7$, and 3.7 V for Devices A, B, C, D, and E, respectively. All five PHOLEDs show similar $J-V$ and luminance-voltage $(L-V)$ characteristics because of similar HOMO and LUMO energy levels. Low turn-on voltages of $2.1 \mathrm{~V}$ for devices A, D, E, and $2.2 \mathrm{~V}$ for Devices B and C were observed. In the described PHOLED structure, the low driving voltage performance is attributed to the insignificant charge trapping and weak charge injection barriers at the interfaces [31, 71-77].

\section{Conclusion}

In this paper, we have presented four main elements that can have a direct control on the efficiency of iridium complex-



FIgURE 16: $J-V-L$ characteristics of fabricated red PHOLEDs.

based PhOLEDs: exciton confinement, charge trapping, doping concentration, and the dopant molecular structure. We have demonstrated through our study that the host matrix HOMO and LUMO energy levels in comparison with the dopant levels in one hand and with the adjacent charge injection layers levels in the other hand, is the common denominator for exciton confinement, charge trapping, dopant concentration, and dopant molecular strucuture.

We have also shown the effects of exciton confinement using CTP host matrix doped with $\operatorname{Ir}(\mathrm{ppy})_{3}$ for green PhOLEDs. Improvement of electron and hole blocking properties of the PhOLED by only changing the EML's adjacent layers from the structure ITO/NPB/CTP: $\operatorname{Ir}(\mathrm{ppy})_{3} /$ BAlq/Alq $/$ / $\mathrm{LiF} / \mathrm{Al}$ to ITO/NPB/TCTA/CTP : $\operatorname{Ir}(\mathrm{ppy})_{3} / \mathrm{Bphen} /$ $\mathrm{LiF} / \mathrm{Al}$ was observed. By implementing such configuration, we increased the luminous efficacy from $10.82 \mathrm{~lm} / \mathrm{W}$ to $27.19 \mathrm{~lm} / \mathrm{W}$, the current efficiency from $21.93 \mathrm{~cd} / \mathrm{A}$ to $38.81 \mathrm{~cd} / \mathrm{A}$ while lowering the driving voltage from $6.5 \mathrm{~V}$ to $4.7 \mathrm{~V}$. 
Furthermore, we showed that the charge trapping can be controlled through the width of the host gap compared to the dopant, the wider energy difference can result the more charge trapping effect. That was illustrated with green dopant $\operatorname{Ir}(\text { ppy })_{3}$ and two different host matrices CBP and Bepp 2 . Since CBP has a wider HOMO-LUMO gap than $\mathrm{Bepp}_{2}$, we have shown that the charge trapping will be consecutively more important and as a result the driving voltage for the CBP based PhOLED is $6.8 \mathrm{~V}$ compared to $5.4 \mathrm{~V}$ for $\mathrm{Bepp}_{2}$ for the same brightness.

The doping concentration that is tightly connected to charge trapping was proven to be adjustable to a minimum, once the energy mismatch was set to a minimum to reduce charge trapping. Such a fact was proven by our comparative study in green PhOLEDs, showing an optimum doping concentration under $2 \%$ for $\mathrm{Bepp}_{2}$ matrix doped with $\operatorname{Ir}(\mathrm{ppy})_{3}$ for green PhOLEDs.

The importance of the molecular structure of the dopant manifests by giving the possibility to tune the HOMO and LUMO levels of the dopant. In response, this had an effect on the efficiency of the final device, as we have proven earlier through the importance of the energy difference between the host and the dopant LUMOs' and HOMOs' energies.

Charge trapping and doping concentration are tightly connected as presented in this paper, nevertheless, we have shown that the doping concentration can be reduce to its minimum once the charge trapping itself is reduced to a minimum by minimizing the energy levels differences between the host and the dopant.

The relation between exciton confinement and charge trapping might also be a point of focus, as a better exciton blocker will have an influence in the electron and hole injection, but that should be tuned to result in a higher efficiency device.

In conclusion, we have demonstrated that four main elements: exciton confinement, charge trapping, dopant concentration, and dopant molecular structure directly affect the performance of the presented red and green PhOLEDs. These factors are dependent on each other and individually predominant depending on the situation.

\section{Acknowledgment}

This work was supported by the IT R\&D Program of MKE/ KEIT (10030834).

\section{References}

[1] Y. Sun, N. C. Giebink, H. Kanno, B. Ma, M. E. Thompson, and S. R. Forrest, "Management of singlet and triplet excitons for efficient white organic light-emitting devices," Nature, vol. 440, no. 7086, pp. 908-912, 2006.

[2] J. Endo, T. Matsumoto, and J. Kido, "Organic electroluminescent devices having metal complexes as cathode interface layer," Japanese Journal of Applied Physics, vol. 41, pp. L800L803, 2002.

[3] W. J. Lee, Y. K. Fang, H.-C. Chiang et al., "Improving turn on voltage and driving voltage of organic electroluminescent devices with nitrogen doped electron transporter," Solid-State Electronics, vol. 47, p. 927, 2003.
[4] I. Tanaka, Y. Tabata, and S. Tokito, "Energy-transfer and lightemission mechanism of blue phosphorescent molecules in guest-host systems," Chemical Physics Letters, vol. 400, no. 1-3, pp. 86-89, 2004.

[5] G. He, O. Scvhneider, D. Qin, X. Zhou, M. Pfeiffer, and K. Leo, "Very high-efficiency and low voltage phosphorescent organic light-emitting diodes based on a p-i-n junction," Journal of Applied Physics, vol. 95, p. 5773, 2004.

[6] P. Wellermann, M. Hofmann, O. Zeika et al., "High-efficiency p-i-n organic light-emitting diodes with long lifetime," Journal of the Society for Information Display, vol. 13, no. 5, pp. 393397, 2005.

[7] J. Meyer, S. Hamwi, T. Bulow, H.-H. Johannes, T. Riedl, and W. Kowalsky, "Highly efficient simplified organic light emitting diodes," Applied Physics Letters, vol. 91, p. 113506, 2007.

[8] J. G. Jang and H. K. Shin, "High efficiency green phosphorescent organic light emitting device with (TCTA/ TCTA0.5TPBi0.5/TPBi): $\operatorname{Ir}($ ppy)3 emission layer," Thin Solid Films, vol. 517, no. 14, pp. 4122-4126, 2009.

[9] Q. Xin, W. L. Li, W. M. Su et al., "Emission mechanism in organic light-emitting devices comprising a europium complex as emitter and an electron transporting material as host," Journal of Applied Physics, vol. 101, Article ID 044512, 2007.

[10] Y.-H. Niu, M. S. Liu, J.-W. Ka, and A. K.-Y. Jen, "Thermally crosslinked hole-transporting layers for cascade hole-injection and effective electron-blocking/exciton-confinement in phosphorescent polymer light-emitting diodes," Applied Physics Letters, vol. 88, Article ID 093505, 2006.

[11] X. W. Chen, W. C. H. Choy, C. J. Liang, P. K. A. Wai, and $\mathrm{S}$. He, "Modifications of the exciton lifetime and internal quantum efficiency for organic light-emitting devices with a weak/strong microcavity," Applied Physics Letters, vol. 91, Article ID 221112, 2007.

[12] N. Tessler, "Transport and optical modeling of organic lightemitting diodes," Applied Physics Letters, vol. 77, Article ID $1897,2000$.

[13] D. L. Dexter, "A theory of sensitized luminescence in solids," Journal of Chemical Physics, vol. 21, p. 836, 1953.

[14] T. Mori and T. Mizutani, "Application of energy transfer model to partially DCM-doped Alq3 light-emitting diode," Polymers for Advanced Technologies, vol. 8, pp. 471-476, 1997.

[15] L. I. Liu, N. N. Baashkov, C. P. Palsule, S. Gangopadhyay, and W. L. Borst, "Intermolecular energy transfer in binary systems of dye polymers," Journal of Applied Physics, vol. 88, p. 4860, 2000.

[16] C. L. Lee, K. B. Lee, and J. J. Kim, "Polymer phosphorescent light-emitting devices doped with tris(2-phenylpyridine) iridium as a triplet emitter," Applied Physics Letters, vol. 77, p. 2280, 2000.

[17] S. Lamansky, R. C. Kwong, M. Nugent, P. I. Djurovich, and M. E. Thompson, "Molecularly doped polymer light emitting diodes utilizing phosphorescent Pt(II) and Ir(III) dopants," Organic Electronics, vol. 2, no. 1, pp. 53-62, 2001.

[18] S. C. Chang, G. F. He, F. C. Chen, T. F. Guo, and Y. Yang, "Degradation mechanism of phosphorescent-dye-doped polymer light-emitting diodes," Applied Physics Letters, vol. 79, p. 2088, 2001.

[19] P. A. Lane, L. C. Palilis, D. F. O’Brien et al., "Origin of electrophosphorescence from a doped polymer light emitting diode," Physical Review B, vol. 63, no. 23, Article ID 235206, pp. 2352061-2352068, 2001.

[20] D. F. O’Brien, C. Giebeler, R. B. Fletcher et al., "Electrophosphoresence from a doped polymer light emitting diode," Synthetic Metals, vol. 116, no. 1-3, pp. 379-383, 2001. 
[21] M. A. Baldo, D. F. O’Brien, Y. You et al., "Highly efficient phosphorescent emission from organic electroluminescent devices," Nature, vol. 395, no. 6698, pp. 151-154, 1998.

[22] D. F. O'Brien, M. A. Baldo, M. E. Thompson, and S. R. Forrest, "Improved energy transfer in electrophosphorescent devices," Applied Physics Letters, vol. 74, no. 3, pp. 442-444, 1999.

[23] V. Cleave, G. Yahioglu, P. Le Barny, R. Friend, and N. Tessler, "Harvesting Singlet and Triplet Energy in Polymer LEDs," Advanced Materials, vol. 11, p. 285, 1999.

[24] X. Gong, J. C. Ostrowski, G. C. Bazan, D. Moses, and A. J. Heeger, "Red electrophosphorescence from polymer doped with iridium complex," Applied Physics Letters, vol. 81, no. 20, pp. 3711-3713, 2002.

[25] T. Tsuzuki, N. Shirasawa, T. Suzuki, and S. Tokito, "Color tunable organic light-emitting diodes using pentafluorophenylsubstituted iridium complexes," Advanced Materials, vol. 15, no. 17, pp. 1455-1458, 2003.

[26] C. Adachi, M. A. Baldo, S. R. Forrest, and M. E. Thompson, "High-efficiency organic electrophosphorescent devices with tris(2-phenylpyridine)iridium doped into electrontransporting materials," Applied Physics Letters, vol. 77, p. 904, 2000.

[27] A. G. Williams, S. Develay, D. L. Rochester, and L. Murphy, "Optimising the luminescence of platinum(II) complexes and their application in organic light emitting devices (OLEDs)," Coordination Chemistry Reviews, vol. 252, p. 2596, 2008.

[28] P. I. Kvam, M. V. Puzyk, K. P. Balashev, and J. Songstad, "Spectroscopic and electrochemical properties of some mixedligand cyclometalated platinum(II) complexes derived from 2phenylpyridine," Acta Chemica Scandinavica, vol. 49, p. 335, 1995.

[29] J. Brooks, Y. Babayan, S. Lamansky et al., "Synthesis and characterization of phosphorescent cyclometalated platinum complexes," Inorganic Chemistry, vol. 41, no. 12, pp. 30553066, 2002.

[30] J. S. Park, W. S. Jeon, J. H. Yu, R. Pode, and J. H. Kwon, "Efficiency optimization of green phosphorescent organic light-emitting device," Thin Solid Films, vol. 519, no. 10, pp. 3259-3263, 2011.

[31] W. S. Jeon, T. J. Park, S. Y. Kim, R. Pode, J. Jang, and J. H. Kwon, "Ideal host and guest system in phosphorescent OLEDs," Organic Electronics, vol. 10, no. 2, pp. 240-246, 2009.

[32] R. C. Kwong, M. R. Nugent, L. Michalski et al., "High operational stability of electrophosphorescent devices," Applied Physics Letters, vol. 81, no. 1, pp. 162-164, 2002.

[33] J. H. Yu, W. S. Jeon, J. S. Park, R. Pode, and J. H. Kwon, "Low-voltage, simple-structure, high-efficiency p-i-n-type electrophosphorescent blue organic light-emitting diodes," Japanese Journal of Applied Physics, vol. 49, no. 10, pp. 1021021-1021024, 2010.

[34] H. S. Lee, S. Y. Ahn, J. H. Seo, Y. K. Kim, and Y. Ha, "Synthesis and luminescence study of red phosphorescent iridium pyrazolonate complexes for OLED," Journal of the Korean Physical Society, vol. 55, p. 1977, 2009.

[35] T. Wakimoto, Y. Fukuda, K. Nagayama, A. Yokoi, H. Nakada, and M. Tsuchida, "Organic EL cells using alkalinemetal compounds as electron injection materials," IEEE Transactions on Electron Devices, vol. 44, no. 8, pp. 1245-1248, 1997.

[36] F. C. Chen, G. He, and Y. Yang, "Triplet exciton confinement in phosphorescent polymer light-emitting diodes," Applied Physics Letters, vol. 82, p. 1006, 2003.
[37] M. A. Baldo, S. Lamansky, P. E. Burrows, M. E. Thompson, and S. R. Forrest, "Very high-efficiency green organic lightemitting devices based on electrophosphorescence," Applied Physics Letters, vol. 75, no. 1, pp. 4-6, 1999.

[38] W. S. Jeon, C. Kulshreshtha, J. H. Yu, M. J. Lim, J. S. Park, and J. H. Kwon, "High efficiency green phosphorescent OLEDs with triplet exciton confinement architecture," Current Applied Physics, vol. 11, no. 3, pp. 311-314, 2011.

[39] J. Y. Lee, "Effect of doping profile on the lifetime of green phosphorescent organic light-emitting diodes," Applied Physics Letters, vol. 89, Article ID 153503, 2006.

[40] S. H. Kim, J. Jang, K. S. Yook, and J. Y. Lee, "Stable efficiency roll-off in phosphorescent organic light-emitting diodes," Applied Physics Letters, vol. 92, Article ID 023513, 2008.

[41] R. J. Holmes, S. R. Forrest, Y. J. Tung et al., "Blue organic electrophosphorescence using exothermic host-guest energy transfer," Applied Physics Letters, vol. 82, no. 15, pp. 24222424, 2003.

[42] R. J. Holmes, B. W. D’Andrade, S. R. Forrest, X. Ren, J. Li, and M. E. Thompson, "Efficient, deep-blue organic electrophosphorescence by guest charge trapping," Applied Physics Letters, vol. 83, no. 18, pp. 3818-3820, 2003.

[43] X. Ren, J. Li, R. J. Holmes, P. I. Djurovich, S. R. Forrest, and M. E. Thompson, "Ultrahigh energy gap hosts in deep blue organic electrophosphorescent devices," Chemistry of Materials, vol. 16, no. 23, pp. 4743-4747, 2004.

[44] M. H. Tsai, H. W. Lin, H. C. Su et al., "Highly efficient organic blue electrophosphorescent devices based on 3,6bis(triphenylsilyl)carbazole as the host material," Advanced Materials, vol. 18, p. 1216, 2006.

[45] M. F. Wu, S. J. Yeh, C. T. Chen et al., "The quest for highperformance host materials for electrophosphorescent blue dopants," Advanced Functional Materials, vol. 17, p. 1887, 2007.

[46] B. D. Chin, M. C. Suh, M. H. Kim, S. T. Lee, H. D. Kim, and H. K. Chung, "Carrier trapping and efficient recombination of electrophosphorescent device with stepwise doping profile," Applied Physics Letters, vol. 86, Article ID 133505, 2005.

[47] Y. Kawamura, K. Goushi, J. Brooks, J. J. Brown, H. Sasabe, and C. Adachi, "100\% phosphorescence quantum efficiency of Ir(III) complexes in organic semiconductor films," Applied Physics Letters, vol. 86, Article ID 071104, 2005.

[48] T. J. Park, W. S. Jeon, J. J. Park et al., "Driving voltage reduction and efficiency increase by narrow bandgap host materials in phosphorescent organic light-emitting diodes," Thin Solid Films, vol. 517, no. 2, pp. 896-900, 2008.

[49] N. Matsusue, S. Ikame, Y. Suzuki, and H. Naito, "Charge carrier transport in an emissive layer of green electrophosphorescent devices," Applied Physics Letters, vol. 85, no. 18, pp. 4046-4048, 2004.

[50] A. Sustikov, Y. You, M. E. Thompson, and B. J. Schwartz, "Electroluminescence color tuning by dye doping in organic light-emitting diodes," IEEE Journal of Selected Topics in Quantum Electronics, vol. 4, pp. 3-13, 1998.

[51] F. Pschenitzka and J. C. Sturm, "Excitation mechanisms in dye-doped organic light-emitting devices," Applied Physics Letters, vol. 79, p. 4354, 2001.

[52] M. Uchida, C. Adachi, T. Koyama, and Y. Taniguchi, "Charge carrier trapping effect by luminescent dopant molecules in single-layer organic light emitting diodes," Journal of Applied Physics, vol. 86, no. 3, pp. 1680-1687, 1999. 
[53] J. Shen and J. Yang, "Physical mechanisms in double-carrier trap-chargelimited transport processes in organic electroluminescent devices: a numerical study," Journal of Applied Physics, vol. 83, p. 7706, 1998.

[54] J. Yang and J. Shen, "Doping effects in organicelectroluminescent devices," Journal of Applied Physics, vol. 84, p. 2105, 1998.

[55] L. I. Liu, N. N. Barashkov, C. P. Palsule, S. Gangopadhyay, and W. L. Borst, "Intermolecular energy transfer in binary systems of dye polymers," Journal of Applied Physics, vol. 88, no. 8, pp. 4860-4870, 2000.

[56] I. Tanaka and S. Tokito, "Energy-transfer processes between phosphorescent guest and fluorescent host molecules in phosphorescent OLEDs," in Highly Efficient OLEDs with Phosphorescent Materials, H. Yersin, Ed., Wiley-VCH, Weinheim, Germany, 2008.

[57] T. Förster, "10th Spiers Memorial Lecture. Transfer mechanisms of electronic excitation," Discussions of the Faraday Society, vol. 27, pp. 7-17, 1959.

[58] D. L. Dexter, "A theory of sensitized luminescence in solids," Journal of Chemical Physics, vol. 21, no. 5, pp. 836-850, 1953.

[59] T. Tsuzuki and and S. Tokito, "Highly efficient and lowvoltage phosphorescent organic light-emitting diodes using an iridium complex as the host material," Advanced Materials, vol. 19, pp. 276-280, 2007.

[60] H. H. Liao, H. F. Meng, S. F. Horng et al., "Triplet exciton energy transfer in polyfluorene doped with heavy metal complexes studied using photoluminescence and photoinduced absorption," Physical Review B, vol. 74, Article ID 245211, 2006.

[61] V. Adamovich, J. Brooks, A. Tamayo et al., "High efficiency single dopant white electrophosphorescent light emitting diodesy," New Journal of Chemistry, vol. 26, no. 9, pp. 11711178, 2002.

[62] C. Adachi, M. E. Thompson, and S. R. Forrest, "Architectures for efficient electrophosphorescent organic lightemitting devices," IEEE Journal on Selected Topics in Quantum Electronics, vol. 8, no. 2, pp. 372-377, 2002.

[63] S. Tokito, T. Iijima, Y. Suzuri, H. Kita, T. Tsuzuki, and F. Sato, "Confinement of triplet energy on phosphorescent molecules for highly-efficient organic blue-light-emitting devices," Applied Physics Letters, vol. 83, no. 3, pp. 569-571, 2003.

[64] W. S. Jeon, T. J. Park, S. Y. Kim, R. Pode, J. Jang, and J. H. Kwon, "Low roll-off efficiency green phosphorescent organic lightemitting devices with simple double emissive layer structure," Applied Physics Letters, vol. 93, Article ID 063303, 2008.

[65] S. H. Kim, J. Jang, and J. Y. Lee, "Relationship between host energy levels and device performances of phosphorescent organic light-emitting diodes with triplet mixed host emitting structure," Applied Physics Letters, vol. 91, Article ID 083511, 2007.

[66] M. Ikai, S. Tokito, Y. Sakamoto, T. Suzuki, and Y. Taga, "Highly efficient phosphorescence from organic light-emitting devices with an exciton-block layer," Applied Physics Letters, vol. 79, no. 2, pp. 156-158, 2001.

[67] S. Watanabe, N. Ide, and J. Kido, "High-efficiency green phosphorescent organic light-emitting devices with chemically doped layers," Japanese Journal of Applied Physics, vol. 46, p. 1186, 2007.

[68] N. Matsumoto, T. Miyazaki, M. Nishiyama, and C. Adachi, "Efficient deep-blue organic light-emitting diodes based on
9,9-Bis(4-biphenylyl)fluorene derivatives," Journal of Physical Chemistry C, vol. 113, no. 15, pp. 6261-6266, 2009.

[69] M. A. Baldo, C. Adachi, and S. R. Forrest, “Transient analysis of organic electrophosphorescence. II. Transient analysis of triplet-triplet annihilation," Physical Review B, vol. 62, no. 16, pp. 10967-10977, 2000.

[70] Y. Kawamura, J. Brooks, J. Brown, H. Sasabe, and C. Adachi, "Intermolecular interaction and a concentration-quenching mechanism of phosphorescent $\operatorname{Ir}(\mathrm{III})$ complexes in a solid film," Physical Review Letters, vol. 96, Article ID 017404, 2006.

[71] C. Adachi, M. A. Baldo, S. R. Forrest, S. Lamansky, M. E. Thompson, and R. C. Kwong, "High-efficiency red electrophosphorescence devices," Applied Physics Letters, vol. 78, no. 11, pp. 1622-1624, 2001.

[72] Y. Kawamura, S. Yanagida, and S. R. Forrest, "Energy transfer in polymer electrophosphorescent light emitting devices with single and multiple doped luminescent layers," Journal of Applied Physics, vol. 92, p. 87, 2007.

[73] A. Tsuboyama, H. Iwawaki, M. Furugori et al., "Homoleptic cyclometalated iridium complexes with highly efficient red phosphorescence and application to organic light-emitting diode," Journal of the American Chemical Society, vol. 125, no. 42, pp. 12971-12979, 2003.

[74] M. A. Baldo, M. E. Thompson, and S. R. Forrest, "Phosphorescent materials for application to organic light emitting devices," Pure and Applied Chemistry, vol. 71, no. 11, pp. 20952106, 1999.

[75] J. Y. Lee, "Intramolecular energy transfer in heteroleptic red phosphorescent dopants," Applied Physics Letters, vol. 89, Article ID 223517, 2006.

[76] C. H. Chien, F. M. Hsu, C. F. Shu, and Y. Chi, "Efficient red electrophosphorescence from a fluorene-based bipolar host material," Organic Electronics, vol. 10, no. 5, pp. 871-876, 2009.

[77] Y. L. Tung, S. W. Lee, Y. Chi et al., "Organic light-emitting diodes based on charge-neutral Os(II) emitters: generation of saturated red emission with very high external quantum efficiency," Journal of Materials Chemistry, vol. 15, no. 4, pp. 460-464, 2005. 

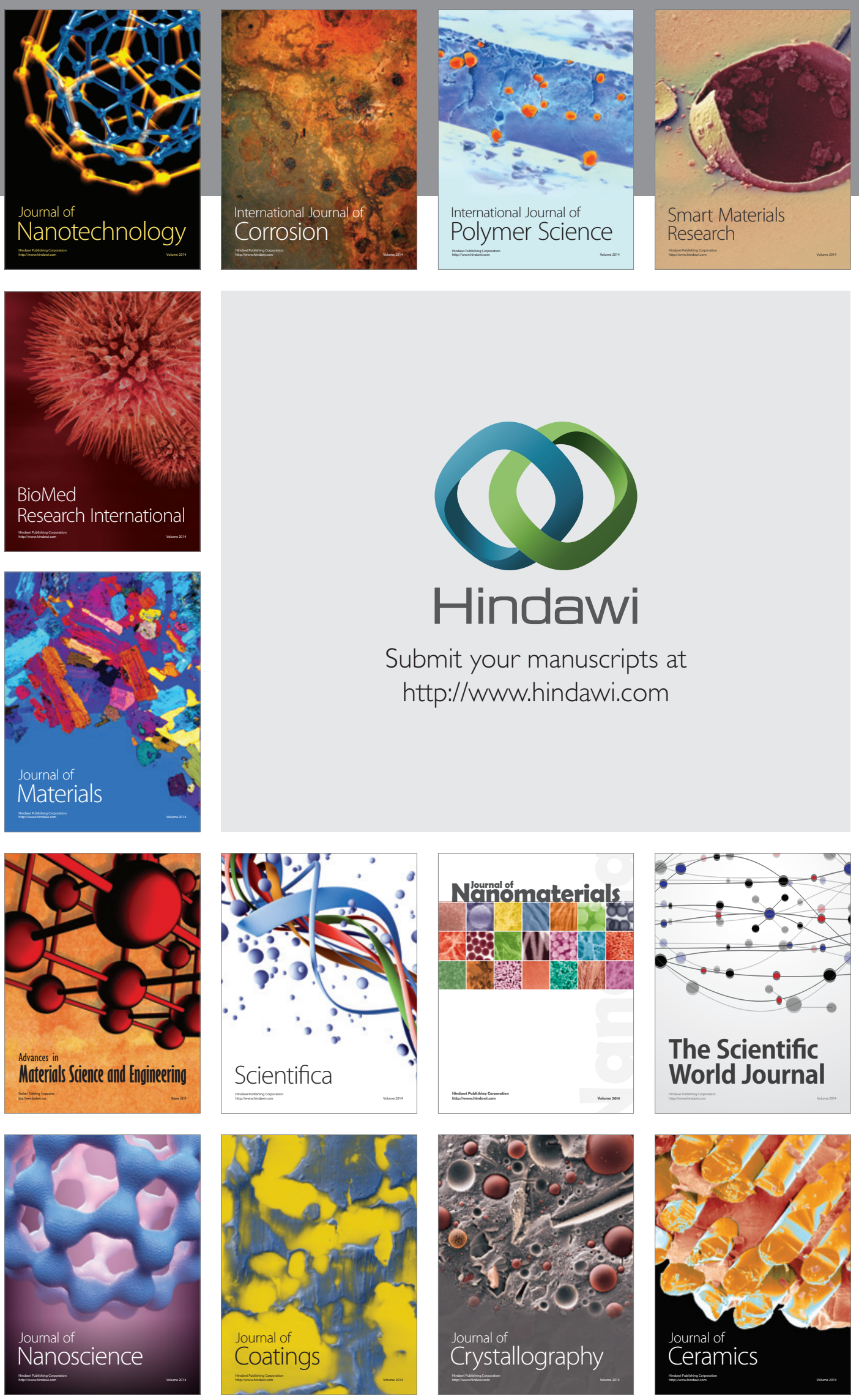

The Scientific World Journal

Submit your manuscripts at

http://www.hindawi.com

\section{World Journal}

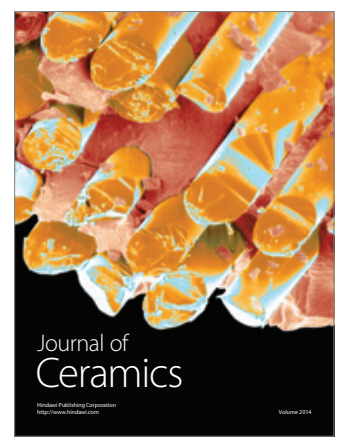

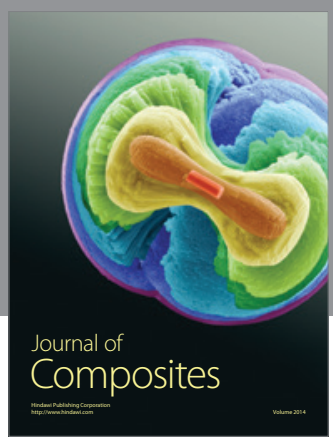
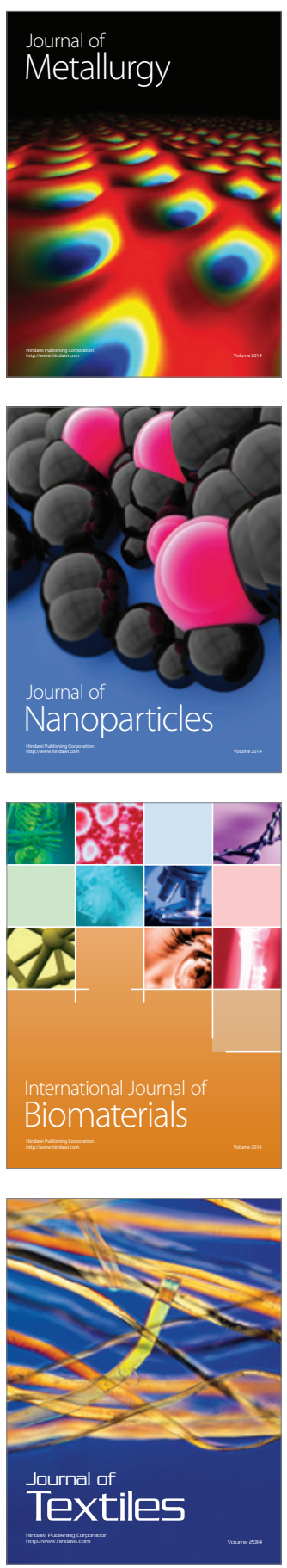